\title{
ARQUEOLOGIA E RESTAURO EM EDIFICAÇÕES INSTÁVEIS SOB A PERSPECTIVA DA SEGURANÇA OCUPACIONAL
}

\author{
Antonio Nunes Barbosa Filhoi
}

'Departamento de Engenharia Civil e Ambiental, Universidade Federal de Pernambuco (UFPE); Professor colaborador dos Programas de Graduação e Pós-Graduação em Arqueologia da UFPE. E-mail: antonio.barbosafo@ufpe.br
Resumo: Projetos arqueológicos voltados para a preservação do patrimônio edificado poderão comumente demandar obras de conservação e/ou restauro, as quais, ao longo de suas distintas fases, por sua natureza e ambiente, poderão sujeitar todos os participantes diretos destes empreendimentos a riscos ocupacionais que, se não mitigados ou controlados, poderão resultar danos aos indivíduos, assim como às construções a preservar e ao andamento dos próprios projetos. A partir do exame do relato do acidente ocorrido nas obras de restauração do Museu Pointe-à-Callière, em Quebec, no Canadá, são apresentados aspectos teóricos e práticos para o adequado planejamento da Segurança ocupacional nas intervenções em edificações instáveis, a fim de assegurar a integridade das pessoas e dos bens materiais envolvidos. Palavras-Chave: Arqueologia e Restauro; Segurança Ocupacional; Condições de Trabalho; Percepção de Riscos.

Abstract: Archaeological projects aimed at the preservation of the built heritage may commonly require conservation and / or restoration works, which, throughout their different phases, due to their nature and environment, may subject all direct participants of these enterprises to occupational risks that, if not mitigated or controlled, damage may result to individuals, as well as to the constructions to be preserved and to the progress of the projects themselves. From the examination of the accident report that occurred in the restoration works of the Pointe-à-Callière Museum, in Quebec, Canada, theoretical and practical aspects are presented for the proper planning of occupational safety in interventions in unstable buildings, in order to ensure the integrity of the people and material goods involved. Key Words: Archaeology and Restoration; Occupational Safety; Work Conditions; Risk Perception. 


\section{Introdução}

Ao longo de suas carreiras, não raro, os profissionais de Arqueologia são convocados a participar de atividades relacionadas à preservação do patrimônio material na forma de edificações em avançado estado de degradação, pela ação do tempo ou pelos mais diversos eventos que resultaram efeitos danosos sobre os seus componentes e estrutura, decorrentes da natureza ou da própria atuação humana, como sismos, incêndios, explosões, erros de construção e, até mesmo, por intervenções anteriores malsucedidas.

Para que possam atuar no interior e periferia dessas edificações, de modo a buscar assegurar a sua própria integridade física, assim como dos membros da equipe arqueológica e de todos os demais profissionais que venham a se integrar ao projeto em curso, posto que a vida de todos esses estará sob a responsabilidade do responsável técnico pela prospecção, uma das primeiras atividades a conduzir será levantar a condição de estabilidade (ou não) dessa edificação. Tal tarefa é de fundamental importância, inclusive para a determinação da amplitude das intervenções que poderão ter lugar e deverá ser realizada a cargo de um engenheiro com domínio técnico na área das seguranças estrutural e laboral associadas, que poderá contar com outros engenheiros em sua equipe, assim como com profissionais de áreas adjacentes como geólogos e arquitetos com atuação prévia em projetos similares.

\section{Dos aspectos técnicos preliminares à intervenção}

Em regra, toda intervenção arqueológica é única. Neste sentido, intervenções em edificações tombadas ou de interesse patrimonial precisam ser bem planejadas e executadas, sobretudo no aspecto da integridade laboral, para que infortúnios não tenham oportunidades de ocorrência, cuja concretização poderá causar prejuízos não só à saúde e segurança de todos os envolvidos nas distintas fases da prospecção e eventuais obras civis, sejam de restauração ou de conservação, bem como ao próprio patrimônio material envolvido e ao andamento dos projetos em si.

A restauração difere da conservação, porquanto aquela compreende as intervenções que contemplam as etapas de estudos e projetos, definição do uso, especificações e execução da 
obra civil até a reocupação da edificação, pelo que se caracteriza em amplitude e complexidade como atividade de médio a grande porte, assim como em duração. Por sua vez, as obras de conservação são de menor envergadura, embora possam ter lugar nesses reparos em pisos, paredes, telhados e outros elementos da estrutura (Najjar \& Duarte, 2002).

Previamente às intervenções visando o início das obras, baseando-se em Barbosa Filho (2015, 59-70), do ponto de vista da Segurança Ocupacional, recomendam-se as seguintes medidas:

1. Verificação in loco da edificação, assim como do entorno imediato, com a sua caracterização e documentação;

2. Elaboração do Plano de Intervenção, etapa por etapa, no tocante ao atendimento simultâneo dos requisitos da exploração arqueológica e de segurança ocupacional; e

3. Estabelecimento dos procedimentos requeridos para a execução segura das atividades para as prospecções e execução das diversas fases da obra civil.

A caracterização do imóvel refere-se à localização, no tocante à disposição no terreno (se isolado ou contíguo a outro imóvel) e quanto ao ambiente onde está inserido (se rural ou urbano).

Quanto à configuração desse imóvel, devem ser analisados:

a) o seu volume e dimensões;

b) a extensão e perímetro de sua área de influência;

c) materiais da construção original; e,

d) estrutura, verificando-se o estado ou condição e seus elementos construtivos e de seu conjunto. Neste sentido, pode-se qualificar o grau de comprometimento da construção original e a extensão das obras civis para a sua reconstrução.

De posse dessas informações básicas, será devido conhecer em que condições terá lugar a exploração arqueológica e as obras civis, sendo necessário buscar dados quanto:

a) Ao nível ou múltiplos níveis em que se darão as intervenções (ao nível do solo, em altura, abaixo do solo ou em situação variável);

b) O momento das intervenções em relação aos elementos do clima (temperatura, ventos, chuvas e outros fenômenos);

c) O solo onde se encontra a edificação e suas características (topografia, altitude, o subsolo e eventuais movimentos); e

d) Normativas aplicáveis (patrimônio histórico, meio ambiente, trânsito, destinação de resíduos, seguros obrigatórios etc.).

Acrescente-se como mandatório o levantamento do seguinte conjunto de informações: 
1) Conhecer a técnica construtiva existente, tanto quanto possível;

2) Estimar as alterações dos esforços estruturais, etapa por etapa de ambas as intervenções e colocar testemunhos para o controle de eventuais deformações ${ }^{1}$;

3) Realizar inspeções prévias, incluindo o entorno e vizinhança, com o registro de imagens;

4) Avaliar o estado de conservação de cada pavimento ou ambiente de intervenção;

5) Averiguar atividades prévias para identificar riscos adicionais em razão das ocupações anteriores (fábricas, hospitais, depósitos em geral etc.);

6) Indagar sobre ou levantar eventuais modificações na obra original, junto a proprietários, antigos usuários do imóvel (se for o caso), bem como nos arquivos públicos e históricos em geral; e

7) Levantar a existência e localização de redes e instalações de água e esgotos, fossas sépticas e de energia (para força e luz) enterradas e planejar o estabelecimento das redes provisórias necessárias e de utilidade ao projeto.

A esta altura os responsáveis pelas intervenções já terão um conjunto de informações sobre como intervir no elemento construído. Contudo, estas somente poderão ser estabelecidas em definitivo a partir do refinamento do até aqui apresentado em confrontação com potenciais situações agravantes, quais sejam:

1) Vícios ocultos e modificações clandestinas (não registradas ao longo da vida da construção e, portanto, desconhecidas);

2) Estados imprecisos (decorrentes de terremotos, deslizamentos inundação, explosão ou outras formas de deterioração, inclusive incêndios, quando os elementos construtivos, apesar de ainda posicionados em sua geometria original, podem ter perdido por completo sua resistência, pelo que incapaz de suportar o peso de trabalhadores e o seu deslocamento sobre estes);

3) O estado específico de construções vizinhas, em especial no caso de aglomerados históricos, onde edificações comumente são contíguas;

4) A dinâmica da retirada e movimentação de materiais provenientes das escavações, assim como para a recomposição de suas aberturas; e

5) Efeitos combinados das situações anteriores.

Passemos à análise de um caso real.

\footnotetext{
1 "Testemunhos" podem ser entendidos como mecanismos de controle e avaliação de patologias em construções, em suas estruturas ou nos materiais que as compõem, em segmentos isolados ou em suas interligações. P. ex. para o controle de deformações, fissuras, movimentação de elementos etc.
} 
O acidente do Museu Pointe-à-Callière, em Quebec, no Canadá:

O museu Pointe-à-Callière integra um importante complexo arqueológico e histórico canadense, sendo considerado o mais importante e mais visitado museu da Cidade de Montreal, cujas obras de restauração resultaram das descobertas feitas nos anos de 1980, na região conhecida como "Velha Montreal" e que veio a ser inaugurado em 1992, como parte das celebrações dos 350 anos de sua fundação ${ }^{2}$.

Para que o museu fosse trazido ao público, uma equipe multidisciplinar, contando com a participação de arqueólogos e de engenheiros terceirizados, por intermédio da contratação de uma empresa especializada, foi estabelecida. Infelizmente, durante as atividades iniciais da prospecção arqueológica, anterior à fase das obras de restauração propriamente ditas, um grave e fatal acidente teve lugar, que foi assim descrito por Barbosa Filho (2019, 176-177):

Experiente arqueólogo, membro da equipe que conduzia estudos exploratórios nos escombros do prédio que abrigou o primeiro Parlamento do Canadá, situado na parte antiga da cidade de Montreal, quando esta foi capital nacional (1843-1849), sofreu grave acidente quando se encontrava realizando escavações no interior da edificação e o piso sob os seus pés ruiu, o que lhe causou severos ferimentos em ambas as pernas, em consequência do que veio a óbito horas mais tarde, mesmo sendo prontamente resgatado e levado a um hospital pelo Corpo de Bombeiros local.

O imóvel, localizado no Mercado de Ste-Anne, fora incendiado em revolta popular ocorrida em 1849. Procedendo as investigações do acidente fatal, as autoridades de saúde e segurança do trabalho da província de Québec, demandaram solidariamente a empresa de arqueologia, à qual o falecido estava vinculado - e por intermédio dela havia sido contratado pelo Museu Pointe-à-Callière para examinar os remanescentes do mercado, assim como as empresas de engenharia contratadas para projetar e implementar as medidas de proteção devidas (escoramentos, acessos temporários etc.).

A equipe de arqueólogos trabalhava na porção mais profunda de um corredor com paredes de 4,8 m de altura, quando estas vieram a colapsar, escoradas inadequadamente, causando a ruptura do piso em que se encontravam e a queda da vítima que teve os membros inferiores atingidos por escombros e terras, o que lhe causou múltiplas fraturas. As multas administrativas aplicáveis, sem prejuízo das indenizações cabíveis, podem alcançar cifras de 10 a 40 mil dólares canadenses.

${ }^{2}$ Mais informações podem ser obtidas no sítio internet do Museu, disponível em: https://pacmusee.qc.ca. Suas coordenadas GPS são: 45,5026 N e 73,5542 ․․ 
Ao que, em continuidade, Barbosa Filho (2019, 177-178), passa a comentar:

Investigações arqueológicas quando conduzidas em antigas edificações ou em suas ruínas não podem prescindir de uma acurada inspeção prévia de suas estruturas e materiais componentes que, por diversas razoes, podem estar comprometidos, do ponto de vista da integridade, logo, no tocante à segurança daqueles que adentram em seu interior.

Estados desconhecidos, quando não existem ou não estão disponíveis registros técnicos acerca do imóvel, suas plantas, instalações e de modificações efetuadas nos projetos originais ao longo de sua existência ou imprecisos, como os resultantes de explosões, inundações, vendavais e outros eventos de semelhante magnitude, impõem a exigência de atenções e cuidados ampliados e, sem dúvida, de contar com a colaboração de profissionais na área de segurança ocupacional aplicada à construção civil, preferentemente com experiência anterior em demolição e atividades correlatas.

É importante, sempre que possível e prevendo possíveis cenários de ocorrências indesejadas resultantes da análise da configuração de cada ambiente dessas construções, planejar, antecipada e consistentemente, as medidas preventivas e protetivas necessárias para a entrada e permanência de trabalhadores em seu interior, assim como as respostas primárias - sobretudo em termos de técnicas, equipamentos e qualificações para que estas sejam levadas a termo em tempo hábil - quando da eventual concretização dessas ocorrências.

No caso em comento, a presença de paredes elevadas e próximas, resultou em situação similar a valas profundas, as quais não devidamente escoradas ou suportadas terminaram por vir abaixo, dando causa ao sinistro. A adequada percepção das condições de risco deve orientar os procedimentos a serem adotados, o número máximo de trabalhadores permitidos por pavimento e em cada espaço, as técnicas para escavação e retirada de materiais, enfim o desenvolvimento da exploração como um todo.

\section{Sobre o atual modelo da Gestão dos Riscos laborais no Brasil}

A mais recente edição da Norma Regulamentadora n. 1 (Brasil, 2020), introduziu uma nova sistemática para o gerenciamento dos riscos laborais no Brasil, que, de modo muito sucinto, pode-se representar no esquema abaixo (Figura 1). 


\begin{tabular}{|c|c|c|}
\hline ETAPAS & DOCUMENTOS & QUAL O RESULTADO ESPERADO? \\
\hline $\begin{array}{c}\text { Identificação } \\
\text { de Perigos }\end{array}$ & & $\begin{array}{l}\text { Identificar e localizar fonte com potencial de } \\
\text { causar lesões ou agravo à saúde. }\end{array}$ \\
\hline $\begin{array}{l}\text { Avaliação de } \\
\text { Riscos }\end{array}$ & Riscos & $\begin{array}{l}\text { - Estabelecer prioridades no trato com os } \\
\text { riscos. } \\
\text { - Nível de risco: severidade x probabilidade }\end{array}$ \\
\hline $\begin{array}{l}\text { Controle de } \\
\text { Riscos }\end{array}$ & Plano de Ação & $\begin{array}{l}\text { - Estabelecer medidas para eliminar, reduzir } \\
\text { ou controlar os riscos; } \\
\text { Definir responsabilidades, cronograma, } \\
\text { formas de acompanhamento e aferição de } \\
\text { resultados }\end{array}$ \\
\hline
\end{tabular}

Figura 1: Representação esquemática simplificada da nova sistemática de gerenciamento de riscos ocupacionais no âmbito normativo laboral brasileiro.

Embora a modificação estabelecida, do ponto de vista técnico não seja de grande impacto sobre as metodologias de levantamento e de avaliação dos riscos ocupacionais e ambientais em si, sua incidência principal se dá no aspecto gerencial, uma vez que se determina o estabelecimento de um programa, que deve ser levado a cabo de maneira contínua e permanente, enquanto existir o empreendimento, sendo atualizado a cada fase, posto que determina a aferição dos resultados almejados no plano gerencial, em especial porque se preconiza a construção de prioridades de intervenção e controle frente aos diferentes níveis de riscos levantados, segundo severidades de consequências e probabilidades de ocorrência de cada uma das oportunidades para a sua concretização, ou seja, é devido e necessário levantar quais são os casos indesejados possíveis, estabelecer suas probabilidades de modo a subsidiar a construção de uma escala de prioridade quanto à sua prevenção e, por fim, para evitar do pior caso entre todos os possíveis, ainda que seja mínima a sua probabilidade, posto que a concretização deste poderá resultar um perda catastrófica ou fatal.

\section{Sobre a responsabilidade e os "crimes" no acidente comentado}

É importante frisar que em se tratando de empreendimento de Arqueologia de Contrato, a responsabilidade pelos riscos, inclusive quanto às suas repercussões na esfera patrimonial, ou seja, aquelas que podem ser revertidas em pecúnia, incidirão sempre sobre o empresário, inclusive na tomada de serviços de terceiros, pela incidência de responsabilidade "in eligendo" (daquele que realizada algo em meu nome ou sob minha coordenação). 
In verbis, o Art. 966 do Código Civil Brasileiro (Brasil, 2002), assim dispõe:

Art. 966. Considera-se empresário quem exerce profissionalmente atividade econômica organizada para a produção ou a circulação de bens ou de serviços.

Dessa definição legal podem ser extraídos os seus principais elementos caracterizadores: interesse econômico, organização do trabalho, profissionalidade (sobretudo com o advento da regulamentação da profissão de Arqueólogo), assunção do risco e direcionamento ao mercado (competição entre distintos ofertantes de mesma categoria econômica, segundo suas capacidades e competências).

De outro lado, quanto à esfera criminal de uma ocorrência laboral, incidente sobre o ente moral ou responsável técnico pelo empreendimento, esta responsabilidade se dá pela simples presença das condições para a ocorrência do infortúnio, não importando, portando, na concretização dos efeitos danosos em concreto. Neste sentido, cabe exemplificar a partir dos seguintes crimes tipificados no Código Penal Brasileiro (Brasil, 1940):

Art. 256 - Causar desabamento ou desmoronamento, expondo a perigo a vida, a integridade física ou o patrimônio de outrem:

Pena - reclusão, de um a quatro anos, e multa.

Art. 258 - Se do crime doloso de perigo comum resulta lesão corporal de natureza grave, a pena privativa de liberdade é aumentada de metade; se resulta morte, é aplicada em dobro. No caso de culpa, se do fato resulta lesão corporal, a pena aumenta-se de metade; se resulta morte, aplica-se a pena cominada ao homicídio culposo, aumentada de um terço.

O núcleo verbal do crime do art. 256 é de duplo mando: causar e expor. Para a não incidência deste comando normativo é preciso não originar e, se concretizado o evento indesejado, não ter exposto alguém a esta possibilidade e nem causado prejuízo patrimonial. Explica-se: a obra desabou no período em que não havia ninguém sujeito aos efeitos deletérios dessa condição. Entretanto, no caso de patrimônio tombado, haverá o ressarcimento ou reparação compensatória a retribuir.

Já o art. 258, explicita o que se convenciona chamar de "formas qualificadas de crime de perigo comum", ou seja, dispõe acerca do comportamento do agente causador e dos efeitos agravantes desse proceder sobre a penalidade no caso de lesão, uma vez que se espera do profissional uma conduta compatível com a preservação da integridade de todos aqueles que atuarem sob sua responsabilidade técnica, coordenação ou interesse. 


\section{Conclusão}

Ao longo deste texto, discorreu-se sobre aspectos da segurança ocupacional no planejamento das intervenções conjugadas de equipes de arqueologia e de construção civil em obras de restauro em edificações instáveis ou de condição estrutural desconhecida, sob a liderança e a responsabilidade técnica de um profissional da primeira, no intuito de assegurar a integridade de todos os participantes do empreendimento; depois se passou ao breve exame de um caso concreto de acidente fatal ocorrido em outro país. Transpondo a situação para uma ocorrência similar no território nacional, se teria a plena incidência dos tipos penais da legislação pátria comentada, sujeitando o arqueólogo responsável pelo projeto às penalidades previstas para estes, razão pela qual esse profissional deve se pautar na observância da legislação trabalhista atinente, cujos principais aspectos técnicos relacionados foram dispostos neste artigo na forma de um roteiro sistematizado para pronta aplicação.

\section{Referência}

BARBOSA FILHO, A. N. 2019. Saúde e Segurança Ocupacional em Arqueologia. Olinda: Babecco. BARBOSA FILHO, A. N. 2015. Segurança do Trabalho na Construção Civil. São Paulo: Atlas.

BRASIL. 2020. Norma Regulamentadora n. 1 - Disposições gerais e Gerenciamento de Riscos Ocupacionais. (Portaria MTb n.o 3.214, de 08 de junho de 1978, atualizada pela Portaria SEPRT n.o 6.730, de 09 de março de 2020).

BRASIL. 2002. Código Civil Brasileiro. Lei Federal n. 10.406, de 10 de janeiro de 2002.

BRASIL. 1940. Código Penal Brasileiro. Decreto-Lei n. 2.848, de 7 de dezembro de 1940.

NAJJAR, R.; DUARTE, M. C. C. 2002. Arqueologia histórica em projetos de restauração: manual. Brasília: Iphan. 